\title{
Em busca de cidades saudáveis: metodologia de análise de indicadores ambientais urbanos em Uberlândia, Minas Gerais ${ }^{1}$
}

In healthy cities search: analysis methodology of urban environmental indicators in Uberlândia, Minas Gerais

En búsqueda de ciudades saludables: metodología de análisis de indicadores ambientales urbanos en Uberlândia, Minas Gerais

Josimar dos Reis de Souza

Mestre e Doutorando em Geografia, PPGeo UFU, Brasil Técnico Administrativo em Educação, IG UFU, Brasil josimarsouza@ufu.br

\section{Beatriz Ribeiro Soares}

Professora Titular, UFU, Brasil brsoares@ufu.br

\footnotetext{
${ }^{1}$ Essa pesquisa é resultado de dissertação de mestrado realizada dentro de Projeto CAPES/FCT, parceria da Universidade Federal de Uberlândia e Universidade de Lisboa.
} 


\section{RESUMO}

O presente estudo teve por objetivo analisar indicadores ambientais da área urbana de Uberlândia a partir de metodologia desenvolvida por Souza (2016), buscando contribuir com novos caminhos e possibilidades de análise da qualidade de vida no intraurbano, via perspectivas do movimento Cidades Saudáveis, que tem se consolidado em várias partes do mundo. Os indicadores foram selecionados tomando como base o Censo Demográfico de 2010 , realizado pelo Instituto Brasileiro de Geografia e Estatística (IBGE). A análise estatística compreendeu três elementos básicos: proporção da presença do indicador no setor censitário pelo valor total desse na cidade; relação do indicador com o número de habitantes/domicílios do setor; e distribuição, dada pela média aritmética entre esses resultados. Os valores obtidos foram normatizados em valores compreendidos entre zero e um e espacializados nos 639 setores urbanos, 69 bairros de Uberlândia e cinco setores urbanos (norte, sul, leste, oeste e central), utilizando Sistema de Informação Geográfica (SIG). A partir da análise foi possível elencar áreas da cidade de que necessitam de maior atenção do poder público, com vistas à construção e consolidação de ambiente urbano mais saudável.

PALAVRAS-CHAVE: Cidades Saudáveis. Qualidade de Vida. Indicadores Ambientais Urbanos.

\section{ABSTRACT}

This study aimed to analyze environmental indicators of the urban area of Uberlândia from methodology developed by Souza (2016), seeking to contribute new ways and possibilities of analysis of the quality of life in intra-urban, via movement of the prospects Healthy Cities, which has It has been established in various parts of the world. The indicators were selected on the basis the Census 2010, conducted by the Brazilian Institute of Geography and Statistics (IBGE). Statistical analysis consisted of three basic elements: proportion of the indicator presence in the census tract for the total value of the city; indicator's relationship to the number of people / households sector; and distribution, given by the arithmetic mean of these results. The values were normalized to values between zero and one and spatialized in 639 urban areas, 69 districts of Uberlândia and five urban areas (north, south, east, west and central) using Geographic Information System (GIS). From the analysis it was possible to list areas of the city that need more attention from the government, with a view to building and consolidating healthier urban environment.

KEYWORDS: Healthy Cities. Quality of life. Urban Environmental Indicators.

\section{RESUMEN}

Este estudio tuvo como objetivo analizar los indicadores ambientales de la zona urbana de Uberlândia de la metodología desarrollada por Souza (2016), tratando de aportar nuevas formas y posibilidades de análisis de la calidad de vida en el comercio intra-urbano, a través del movimiento de las perspectivas de Ciudades Saludables, que tiene se ha establecido en varias partes del mundo. Los indicadores fueron seleccionados sobre la base del censo de 2010, realizado por el Instituto Brasileño de Geografía y Estadística (IBGE). El análisis estadístico consistió en tres elementos básicos: proporción de la presencia indicador en el sector censal para el valor total de la ciudad; la relación del indicador con el número de / sector de los hogares de personas; y la distribución, dado por la media aritmética de los resultados. Los valores se normalizaron a valores entre cero y uno y espacializada en 639 áreas urbanas, 69 distritos de Uberlândia y cinco áreas urbanas (norte, sur, este, oeste y central) usando el Sistema de Información Geográfica (GIS). A partir del análisis fue posible enumerar áreas de la ciudad que necesitan más atención por parte del gobierno, con miras a la construcción y consolidación de entorno urbano más saludable.

PALABRAS-CLAVE: Ciudades Saludables. Calidad de vida. Indicadores Ambientales Urbanos. 


\section{INTRODUÇÃO}

O século XX foi marcado por profundas mudanças na sociedade, sobretudo, pela transição demográfica do campo para as cidades. Estudos da Organização das Nações Unidas (ONU) apontam que mais da metade da população mundial vive em aglomerados urbanos, sendo que diariamente mais de 180 mil pessoas deixam o campo em busca de melhores condições de vida nas cidades. No início do século XIX as cidades concentravam apenas $2 \%$ da população mundial e se prevê que até 2050 mais de dois terços da população viverá em cidades (ONU, 2010).

No Brasil, a partir de 1950 o processo de urbanização se intensificou levando a população para as cidades em busca de trabalho e melhores condições de vida. Isso se deu, sobretudo, pelo estímulo ao processo de industrialização (GOMES; SOARES, 2004). As alterações ocorridas nas décadas seguintes levaram ao retrato atual de grandes diferenças socioeconômicas e de qualidade de vida em um mesmo ambiente urbano, com significativa parcela da população brasileira vivendo em condições precárias, sem acesso a serviços básicos de qualidade, tais como saneamento básico, saúde e educação.

O relatório da ONU (2010) aponta que $28 \%$ da população brasileira (mais de 53 milhões de pessoas) vivem em mais de dezesseis mil áreas inapropriadas para fixação de moradia e/ou em condições mínimas de sobrevivência. A complexidade dos espaços urbanos, com intensos problemas ambientais, conflitos no uso do solo, injustiça social e problemas ligados a qualidade de vida da população, fazem com que seja necessário buscar por soluções que propiciem aos centros urbanos melhores condições para se viver.

[...] intervir sobre as condições de vida, que visem a redução das vulnerabilidades sociais e o desenvolvimento local integrado representam o esforço de negociação entre governo, sociedade civil e cidadãos para buscar o bem-estar das populações (WESTPHAL, 2000, p. 42).

$\mathrm{Na}$ busca por melhorias da qualidade de vida da população tem se intensificado nas últimas décadas os estudos sobre as cidades na perspectiva de se buscar a realização de transformações positivas no espaço urbano. Estes estudos visam discutir os problemas inerentes aos centros urbanos de forma a buscar alternativas para a melhoria da qualidade de vida nas cidades. Um dos movimentos que tem ampliado e difundidos suas discussões e pesquisas é o movimento pela construção de Cidades Saudáveis.

O movimento Cidades Saudáveis surgiu em 1978 no Canadá, quando o governo da cidade de Toronto publicou o relatório "A saúde pública nos anos 1980", defendendo a ideia da implementação de políticas de saúde pública para que Toronto se tornasse a cidade mais saudável da América do Norte (MENDES, 2000). Em suma, a Cidade Saudável é aquela que está continuamente criando e desenvolvimendo seus ambientes físico e social, com foco na saúde, através do Planejamento Urbano e expandindo recursos comunitários que permitam às pessoas apoiarem-se mutuamente nas várias dimensões de sua vida e no desenvolvimento do seu potencial máximo (GOLDSTEIN; KICHBUSCH, 1996). 
Cidades Saudáveis é o nome que se dá a um projeto de desenvolvimento social, que tem a saúde e suas múltiplas determinações como centro das atenções. É também um movimento de luta por um estilo de desenvolvimento sustentável, que satisfaça as necessidades das gerações atuais sem comprometer a capacidade das futuras de satisfazer suas próprias necessidades (GUIMARÃES, 2000, p. 15).

Para o desenvolvimento físico e social da cidade e proposição de Políticas Publicas eficazes (foco da busca pela construção de Cidades Saudáveis), se faz necessário conhecer a cidade e suas diferentes dimensões, que incluem a educação, a saúde, o meio ambiente e desenvolvimento social. Somente a partir da exposição do panorama/realidade da cidade se torna possível definir estratégias de intervenção para a construção de cidades mais saudáveis, seja através da melhoria da qualidade de vida, como também, da diminuição gradativa da exclusão social urbana.

Nesse sentido a busca por parâmetros e indicadores de mensuração da realidade das condições de vida no ambiente urbano se faz necessário, visto que, o resultado dessas análises pode auxiliar na espacialização dos níveis de vida da população no espaço urbano, como também, pode apontar os possíveis rumos necessários para se alcançar estratégias mais eficazes na consolidação de políticas públicas que auxiliem na minimização das desigualdades socioespaciais.

Desde o lançamento da Agenda $21^{2}$ são grandes os esforços a nível mundial, regional e local que buscam consolidar um sistema de indicadores e índices que apoiem o poder público nas tomadas de decisão em relação às políticas de gestão ambiental e de melhoria da qualidade de vida da população (OCDE, 1978).

\begin{abstract}
Nesse sentido, os indicadores assumem ao mesmo tempo dois papeis: o de mostrar se as intervenções das ações do planejamento urbano em determinados espaços urbanos proporcionaram a melhoria da qualidade de vida e diminuição da exclusão social (efetividade ou não da política implementada); e o papel de apresentar espacialmente aos gestores áreas do espaço urbano que necessitam de Políticas Públicas voltadas a solução da carência dos serviços e ações básicas de desenvolvimento social (SOUZA; SOARES, 2014, p. 7).
\end{abstract}

A partir das premissas que constituem o Movimento Cidades Saudáveis, (i) que a Cidade Saudável é constituída através do desenvolvimento dos ambientes físico e social, (ii) que este desenvolvimento é alcançado através de Políticas Públicas urbanas voltadas para a melhoria da qualidade de vida, (iii) que essas Políticas Públicas são pautadas nas intervenções ligadas ao Planejamento Urbano, (iv) e que o estudo de indicadores é um importante instrumento de orientação e avaliação das Políticas Públicas; que o presente estudo visou contribuir com proposta metodológica de análise de indicadores ambientais intraurbanos e sua aplicação da área urbana de Uberlândia, Minas Gerais.

\footnotetext{
${ }^{2}$ A Agenda 21 é um instrumento de planejamento para a construção de sociedades sustentáveis, em diferentes bases geográficas, que concilia métodos de proteção ambiental, justiça social e eficiência econômica (ONU, 2010).
} 
O presente estudo se justificou pela necessidade de desenvolver novos instrumentos que auxiliem na busca pela melhoria da qualidade de vida da população e no gerenciamento do dinheiro público através da execução de Políticas Públicas mais eficazes, que possibilitem o desenvolvimento das cidades e superação dos desafios urbanos. Busca-se com a proposta de índice, contribuir com avanços, através de novas estratégias de análise, para o desenvolvimento de ambientes urbanos mais saudáveis, foco da busca pela construção de Cidades Saudáveis.

\section{METODOLOGIA}

A metodologia de análise de indicadores ambientais intraurbanos foi realizada a partir de proposição metodologia de Souza (2016) e se baseou nos seguintes passos:

\section{Escolha dos indicadores de análise}

O Meio Ambiente no urbano envolve uma série de questões e vai além das áreas verdes e contato com a natureza. Entende-se que o meio ambiente será saudável quando as questões sanitárias possam atender a população em sua totalidade. Nesse sentido, relaciona-se aos serviços urbanos disponíveis a população, como por exemplo, destinação do lixo, esgotamento sanitário, entre outros.

Para a dimensão Meio Ambiente foram escolhidas duas variáveis: limpeza urbana e saneamento básico, conforme figura 1.

Figura 1: Variáveis Ambientais

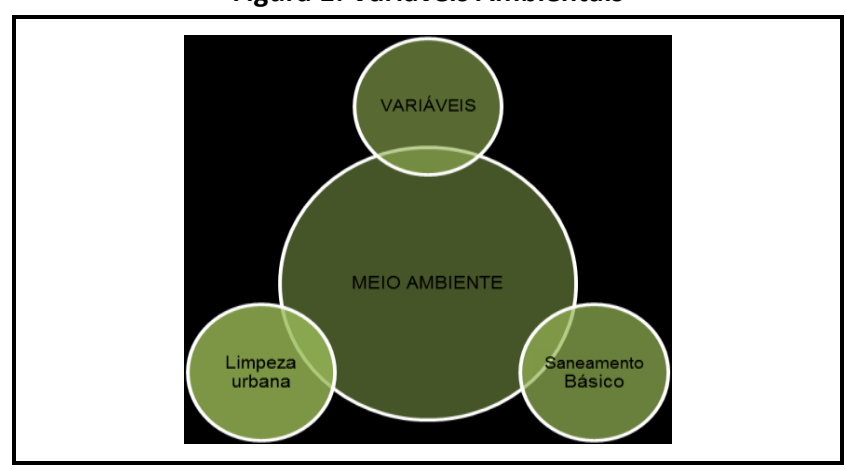

Org.: SOUZA, 2015.

A limpeza urbana diz respeito aos tipos de coleta de resíduos sólidos realizados na cidade e a amplitude desse atendimento na malha urbana. Entende-se que através dela a população tem acesso a ambientes mais limpos. Cabe ressaltar que isso ocorre aliado ao processo de 
conscientização e a educação ambiental, visto que, comumente em áreas atendidas por serviços públicos de limpeza tem quantidade significativa de lixo em terrenos baldios e outros.

O saneamento básico ${ }^{3}$ diz respeito aos serviços de acesso a água, de esgotamento e tratamento sanitário. Sabe-se que as condições de saúde estão intrínsecas a qualidade da água e ao esgoto. Ambientes que não possuem agua tratada e descarte correto de dejetos são áreas propícias à proliferação de doenças.

Para a dimensão Meio Ambiente foi escolhido um indicador para a variável limpeza urbana (coleta de lixo) e dois indicadores para a variável saneamento básico (abastecimento de água e esgotamento sanitário), conforme figura 2.

Figura 2: Indicadores de Meio Ambiente

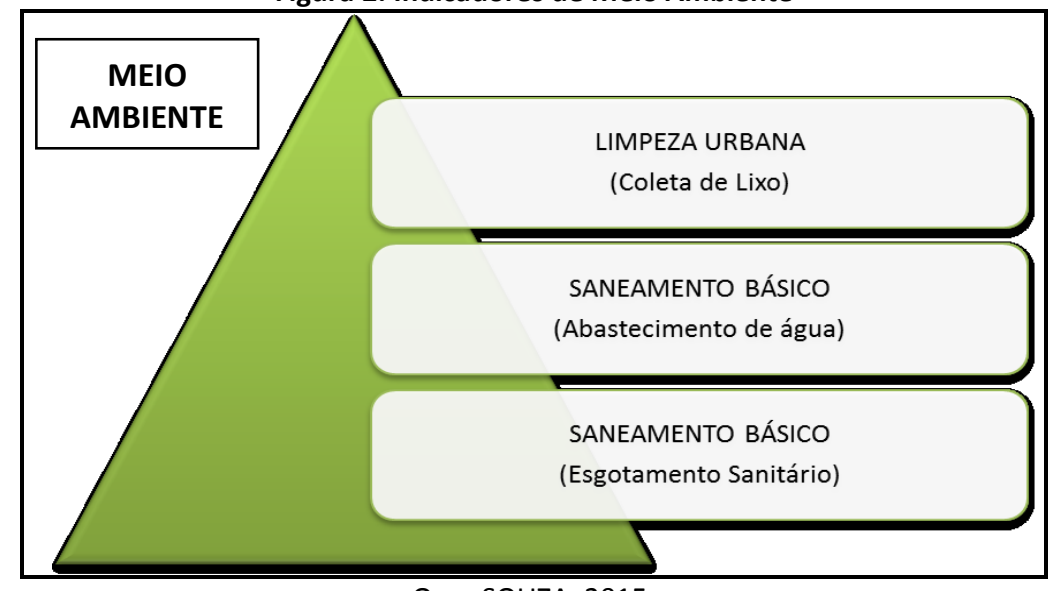

Org.: SOUZA, 2015.

O indicador coleta de lixo diz respeito a presença ou ausência desse serviço urbano, seja pelo diretamente coletado por serviço de limpeza ${ }^{4}$ ou coletado em caçambas ${ }^{5}$. É importante indicador, pois áreas da cidade onde não há esse tipo de atendimento estão propicias a maiores níveis de poluição, visto que a população faz o descarte de outras formas, através da queima, de aterramento, em rios e córregos, entre outros.

$\mathrm{O}$ indicador abastecimento de água apresenta também a qualidade no atendimento na cidade através de rede geral de distribuição ${ }^{6}$. Se determinada área não se encontra abastecida por água tratada a população busca outras maneiras para sua obtenção, através de poços, nascentes, água de chuva e outros. $O$ indicador esgotamento sanitário diz respeito a coleta e destinação dos dejetos produzidos no domicílio. Se em determinada área não há presença de

\footnotetext{
${ }^{3}$ Saneamento básico - conjunto de medidas adotadas em uma região, em uma cidade, para melhorar a vida e a saúde dos habitantes impedindo que fatores físicos de efeitos nocivos possam prejudicar as pessoas no seu bemestar físico mental e social (IBGE, 2010).

${ }^{4}$ Quando o lixo do domićlio é coletado diretamente por serviço de empresa pública ou privada (IBGE, 2010).

${ }^{5}$ Quando o lixo do domicílio era depositado em uma caçamba, tanque ou depósito, fora do domicílio, para depois ser coletado por serviço de empresa pública ou privada (IBGE, 2010).

${ }^{6}$ Quando o domicílio ou o terreno, ou a propriedade onde está localizado, está ligado a uma rede geral de distribuição de água (IBGE, 2010).
} 
rede geral de esgoto ou pluvial $^{7}$ ou de fossa séptica ${ }^{8}$ a população se encontra exposta a riscos de saúde pelos outros métodos utilizados (fossa rudimentar, valas, descartes em rios e outros).

\section{Processos Estatísticos}

\section{Etapa Um - Análise estatística de proporção}

A primeira etapa dos procedimentos estatísticos é a análise da proporção da presença do indicador no setor censitário em relação aos demais da cidade. Faz-se necessária essa análise para compreensão de qual a quantidade da presença do indicador analisado em determinada área em relação ao universo da análise (espaço intraurbano). Desta maneira é possível estabelecer níveis quantitativos de importância dos setores, como por exemplo, os que concentram maior número de domicílios atendidos por água e etc.

Busca-se com a análise da proporção evitar erros na análise do espaço intraurbano. Utilizando, como exemplo, o esgotamento sanitário da dimensão Meio Ambiente, tem-se que um setor pode apresentar indicador esgotamento sanitário com elevado patamar de atendimento (próximo a 100\%), entretanto, nem sempre este poderá ser considerado como sendo mais saudável em relação a outro que apresente patamar intermediário (entre $80 \%$ a $90 \%$ ), visto que, o setor que apresenta patamar intermediário pode apresentar número bem maior de domicílios em relação ao de patamar elevado, com poucos domicílios (distrito industrial, por exemplo). Portanto, conhecer a distribuição do indicador na cidade, relacionando com número de domicílios ou número de habitantes é de suma importância para minimizar distorções.

A figura 3 apresenta o cálculo matemático envolvendo a proporção. Ela se dá pela quantidade do indicador presente no setor censitário pela quantidade do mesmo presente em toda a área urbana.

Figura 3: Análise estatística da Proporção

\[ \text { Pisc }=\frac{\text { Qisc }}{\text { Qic }} \]
Onde:
Pisc - Proporção do indicador do setor censitário.
Qisc - Quantidade do indicador presente no setor censitário.
Qic - Quantidade do indicador presente na cidade.

Org.: SOUZA, 2015.

\section{Etapa Dois - Análise estatística da Relação}

A segunda etapa analítica diz respeito a relação que o indicador do setor censitário tem com o universo dele mesmo. Trata-se da necessidade de buscar uma compreensão mais completa dos indicadores.

\footnotetext{
${ }^{7}$ Rede geral de esgoto ou pluvial - quando a canalização das águas servidas e dos dejetos, proveniente do banheiro ou sanitário, esta ligada a um sistema de coleta que os conduza a um desaguadouro geral da área, região ou município, mesmo que o sistema não disponha de estação de tratamento da matéria esgotada (IBGE, 2010).

${ }^{8}$ Fossa séptica - quando a canalização do banheiro ou sanitário esta ligada a uma fossa séptica, ou seja, a matéria é esgotada para uma fossa próxima, onde passa por um processo de tratamento ou decantação, sendo, ou não, a parte líquida conduzida em seguida para um desaguadouro geral da área, região ou município (IBGE, 2010).
} 
Por exemplo, se analisada a proporção do número de alfabetizados do setor apenas em relação a cidade, a análise se tornaria incompleta, visto que há a necessidade de se entender a presença do indicador não apenas no que diz respeito setor-cidade, mas também, na relação dada pela presença ou ausência desse pelo número total de habitantes do setor. Desta maneira a partir da análise proposta, além da proporção que mostra a quantidade do indicador presentes no setor em relação aos demais da cidade, a relação mostra também a quantidade desses pelo número de habitantes, ou seja, a densidade do indicador. Tal análise propicia a relativização do índice em determinado setor, visto que alguns deles possuem elevado número de habitantes e/ou número de domicílios e outros apresentam menor número desses fatores.

A aplicação estatística da relação é apresentada na figura 4. Ela se dá pela quantidade do indicador presente no setor censitário em relação ao número de habitantes ou de domicílios existentes no setor.

Figura 4: Análise estatística da Relação

\[ \text { Rics = Qisc } \]
Qx
Onde:
Rics - Relação do indicador do setor censitário.
Qisc - Quantidade do indicador presente no setor censitário.
Qx - Quantidade de habitantes ou quantidade de domicílios no setor.

Org.: SOUZA, 2015.

\section{Etapa Três - Análise estatística da Distribuição}

A obtenção da distribuição dos indicadores pela área urbana é realizado a partir da utilização da função média aritmética ponderada presente no software ArcGiS 10.1. Esse procedimento estatístico leva em consideração as variáveis envolvendo a relação e a proporção de cada indicador. Trata-se de cálculo matemático envolvendo a média, mediana e desvio padrão (MANUAL ARCGIS, 2010).

\section{Etapa Quatro - Normatização dos resultados}

A quarta etapa contempla a normatização dos resultados obtidos da proporção, relação e distribuição. Esta é essencial e muito utilizada em análises estatísticas de dados, pois possibilita que os indicadores escolhidos se tornem comparáveis. A fase de normatização seguiu os critérios adotados pelo programa das Nações Unidas para o cálculo do IDH ${ }^{9}$ (Índice de desenvolvimento Humano), adotando o procedimento de normatização dos dados obtidos,

\footnotetext{
${ }^{9} \mathrm{O}$ Índice de Desenvolvimento Humano (IDH) é uma medida resumida do progresso a longo prazo em três dimensões básicas do desenvolvimento humano: renda, educação e saúde. O objetivo da criação do IDH foi o de oferecer um contraponto a outro indicador muito utilizado, o Produto Interno Bruto (PIB) per capita, que considera apenas a dimensão econômica do desenvolvimento (PNUD, 2015).
} 
que em suma é a transformação dos valores reais em valores que compreendem zero e um, tornando possível sua comparação.

A figura 5 apresenta o cálculo de normatização (ONU apud MORATO, 2004), aplicado a todos os indicadores analisados. O calculo se dá pelo valor encontrado no setor censitário menos o valor mínimo encontrado entre todos os da cidade pelo valor máximo menos valor mínimo encontrado nos setores.

Figura 5: Normatização dos dados da proporção e relação

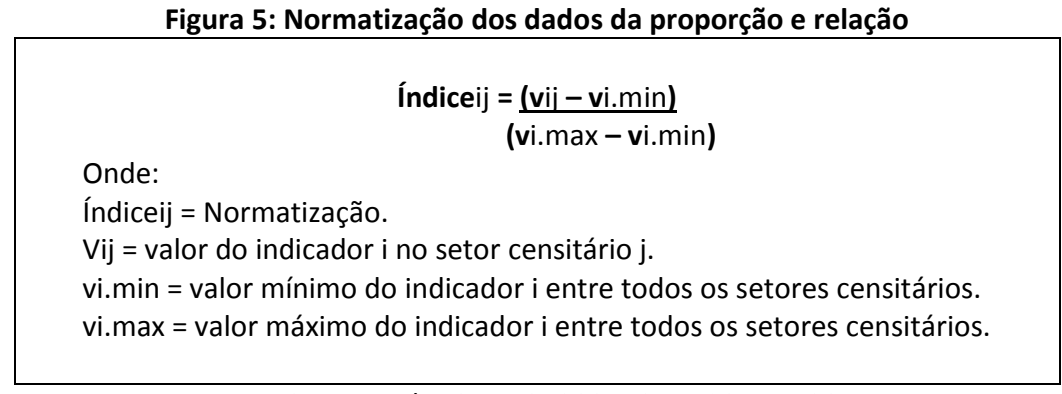

Fonte: ONU apud MORATO, 2004. Org.: SOUZA, 2015.

\section{Etapa Cinco - Escolha das Classes de Análise}

Como se trata de metodologia pensada para analisar o quão saudável a cidade se encontra, os resultados apresentam variação de zero a um, sendo que quanto mais próximo de zero menos saudável é determinado setor e quanto mais próximo de um mais saudável se encontra. Foram definidos cinco níveis de ambiente saudável na cidade: não saudável, nível saudável baixo, nível saudável médio, nível saudável alto, saudável, conforme figura 6.

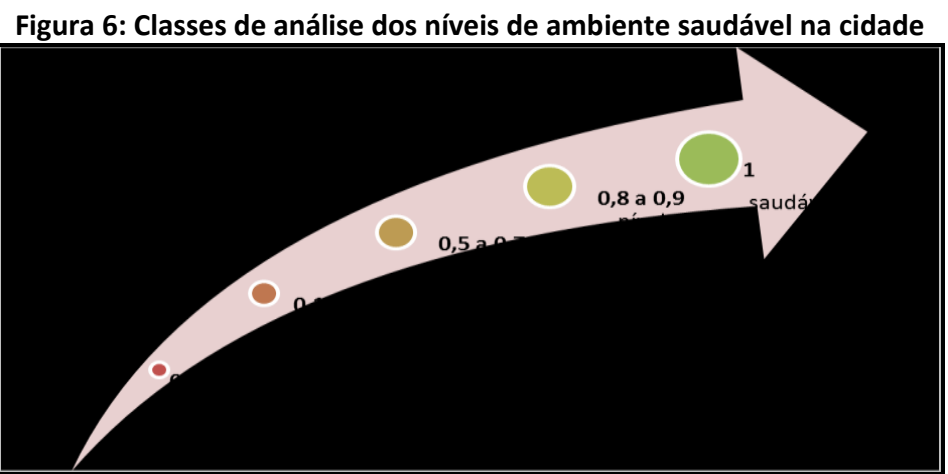

Org.: SOUZA, 2016.

\section{RESULTADOS}

\section{Variável Limpeza Urbana}

A limpeza urbana foi avaliada através do indicador coleta de lixo. Essa diz respeito aos tipos de coleta de resíduos sólidos realizados na cidade e a amplitude desse atendimento na malha 
urbana. Entende-se que a população servida por esse serviço tem acesso a ambientes mais saudáveis.

A figura 7 apresenta o resultado da aplicação do índice nos dados que compõem o indicador serviço domiciliar de coleta de lixo.

A proporção da coleta de lixo foi avaliada a partir do número de domicílios com coleta de lixo do setor censitário em relação ao número total de domicílios com coleta de lixo da área urbana. Essa análise possibilitou a verificação das áreas da cidade com maior quantidade de domicílios com atendimento do serviço de coleta.

A proporção em Uberlândia no ano de 2010 demonstrou que a maior parte dos setores censitários apresentaram entre sete e 335 domicílios com serviço de coleta de lixo (0,001 $0,400)$, sendo que, o setor censitário com maior número se localiza no bairro São Jorge. Esse setor é o com maior número de domicílios, conforme explicitado na análise da distribuição domiciliar, e por isso apresenta alta demanda por serviços básicos.

A relação foi averiguada a partir do número de domicílios com coleta de lixo em relação ao número total de domicílios do setor censitário. Essa relação equivale a densidade da coleta de lixo e representa as áreas da cidade com maior e menor nível de coleta de lixo por habitante.

O resultado da análise da relação demonstrou que Uberlândia apresenta altos níveis de coleta de lixo domiciliar, sendo que na maior parte dos setores censitários todos os domicílios são atendidos (densidade de coleta de lixo igual 1,000), seguido por setores nos quais a maior parte dos domicílios receberam atendimento da coleta de lixo (densidade de coleta de lixo entre 0,769 e 0,998$)$.

A distribuição dos domicílios com coleta de lixo foi realizada através da média aritmética entre os resultados da proporção e relação. Esses foram normatizados entre zero e um. Os resultados da distribuição apontaram que a cidade de Uberlândia, ano de 2010 possuía bons níveis de coleta de lixo. As zonas sul e leste foram as que apresentaram setores com maior nível. A exceção ficou para o setor censitário localizado no bairro Dom Almir, que diz respeito a setor com nível baixo de distribuição de habitantes e domicílios, localizado em área da cidade com nível baixo de distribuição de renda. 
Figura 7: Uberlândia/MG: Proporção, Relação e Distribuição do serviço de coleta de lixo

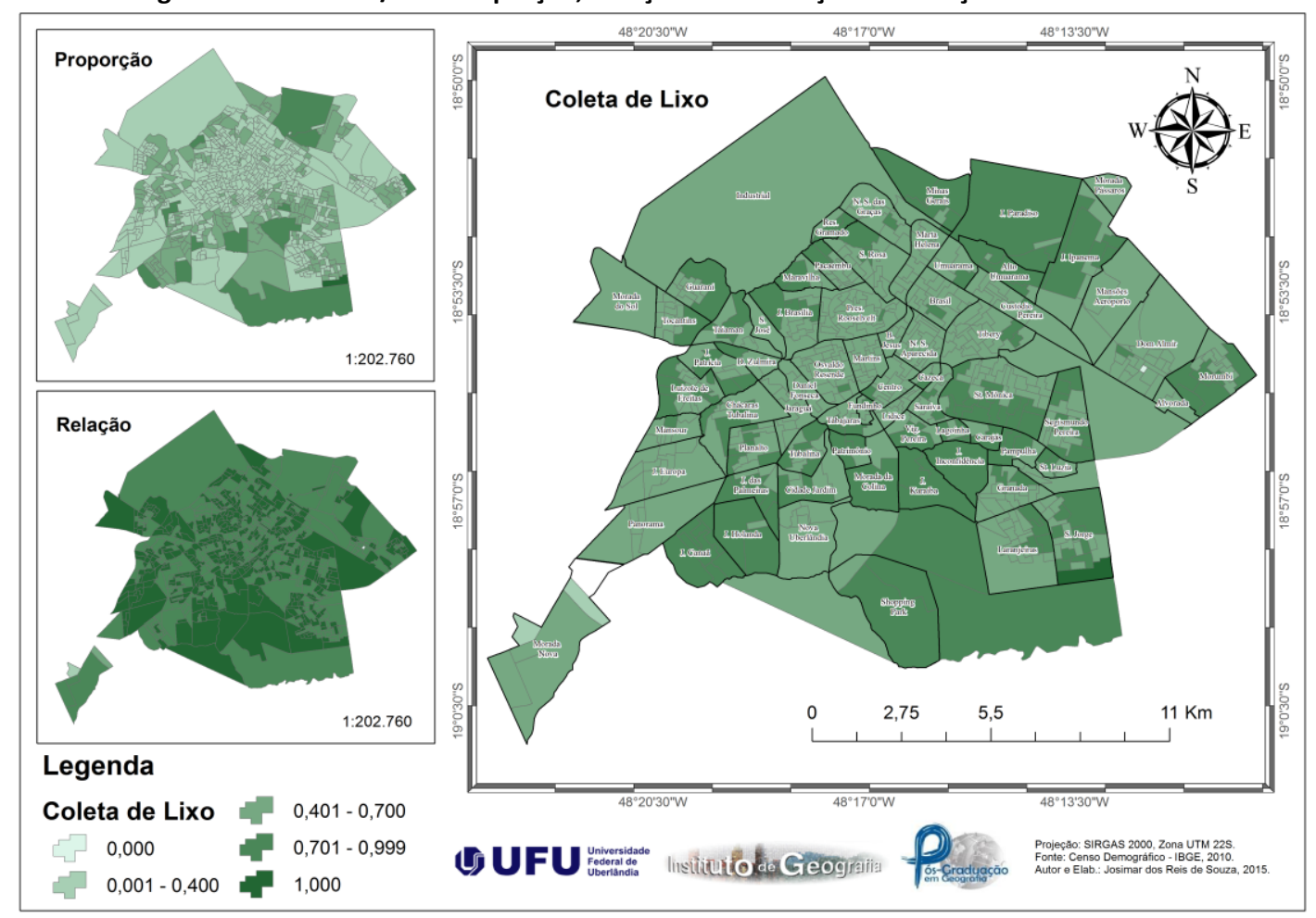

Fonte: IBGE, 2010. Elaborado por: SOUZA, 2015.

Todos os 69 bairros existentes em Uberlândia no ano de 2010 apresentaram nível alto e médio de distribuição de coleta de lixo. Esses dados apontam a elevada cobertura dos serviços realizados pela empresa Limpebrás. Os bairros com melhores resultados são os que possuem maior número de domicílios, sendo muitos deles localizados em áreas de menor renda. Em contrapartida bairros com alta e média renda foram classificados com nível médio por possuírem menor número de domicílios. Entretanto, esses também apresentaram considerável nível cobertura, próxima a 100\%.

A Prefeitura Municipal de Uberlândia tem realizado importantes ações na melhoria dos serviços de coleta de lixo. No ano de 2010 foi inaugurado o novo aterro sanitário de Uberlândia. Esse mesmo aterro recebeu em 2013 o Prêmio Ouro da Secretaria de Meio Ambiente de Minas Gerais como sendo o melhor de Minas, com destinação correta do lixo (LIMPEBRÀS, 2015).

No ano de 2010 Uberlândia iniciou também a coleta seletiva de lixo, sendo que por iniciativa do governo federal foram construídos dois galpões para que os catadores conveniados a cooperativas pudessem realizar seus trabalho. A coleta seletiva é realizada com caminhado adaptado que passa semanalmente em todos os bairros de Uberlândia.

Entretanto, mesmo com a ampla cobertura do serviço de limpeza urbana, é possível identificar no cotidiano, áreas da cidade com grande volume de lixo em terrenos, nas entradas da cidade, nos bairros periféricos, nas margens dos cursos de água, entre outros. Tais aspectos apontam que a cobertura de determinado serviço não é suficiente para construção de ambientes saudáveis. Essa deve ser aliada a programas ambientais e demais estratégias auxiliem na superação desse problema urbano. 
A figura 8 mostra áreas utilizadas como depósitos de lixo e entulho as margens do anel viário de Uberlândia. A figura 9 aponta a situação dos cursos hídricos, com presença de lixo no Rio Uberabinha.

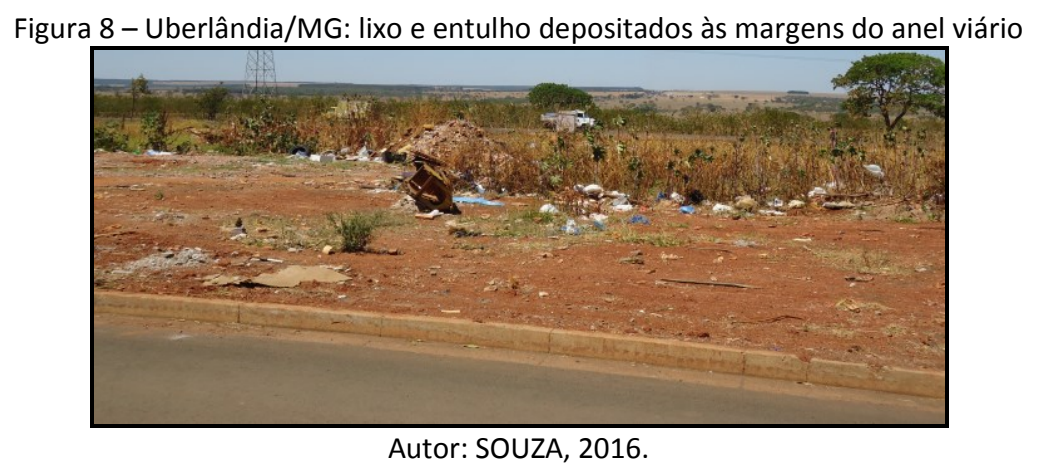

Figura 9 - Uberlândia/MG: lixo presente no Rio Uberabinha

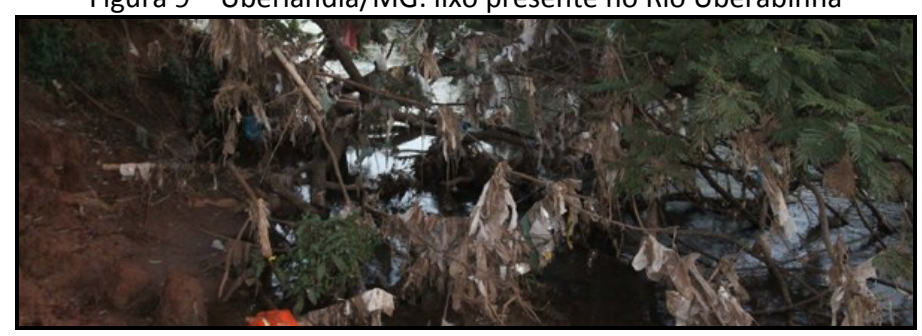

Fonte: Correio de Uberlândia, 2013.

\section{Variável Saneamento Básico}

A variável saneamento básico foi analisada a partir dos indicadores de abastecimento de água tratada e esgotamento sanitário. O primeiro apresenta a qualidade no atendimento de água na cidade através de rede geral de distribuição. $\mathrm{O}$ segundo diz respeito a destinação dos dejetos produzidos no domicílio.

No ano de 2015 Uberlândia foi eleita como melhor cidade em Saneamento Básico do país, com $100 \%$ dos domicílios atendidos pelo abastecimento de água e $99 \%$ dos domicílios com tratamento de esgoto (CORREIO DE UBERLÂNDIA, 2015). A pesquisa realizada pelo Instituto Trata Brasil utilizou dados oficiais do Censo Demográfico e disponibilizados pelo Departamento Municipal de Água e Esgoto (DMAE). Entretanto, de acordo com o diretor do DMAE 6.228 habitantes ainda se encontram sem acesso a rede de esgoto.

A partir dos dados apresentados faz-se necessário analisar a distribuição do abastecimento de água e esgotamento sanitário na área urbana de Uberlândia no sentido de identificar as áreas da cidade que ainda não possui total acesso a esses serviços.

\section{Abastecimento de Água}

A figura 10 apresenta o resultado da aplicação do índice, através da proporção, relação e distribuição da rede de abastecimento de água em Uberlândia no ano de 2010. 
Figura 10: Uberlândia/MG: Proporção, Relação e Distribuição do serviço de abastecimento

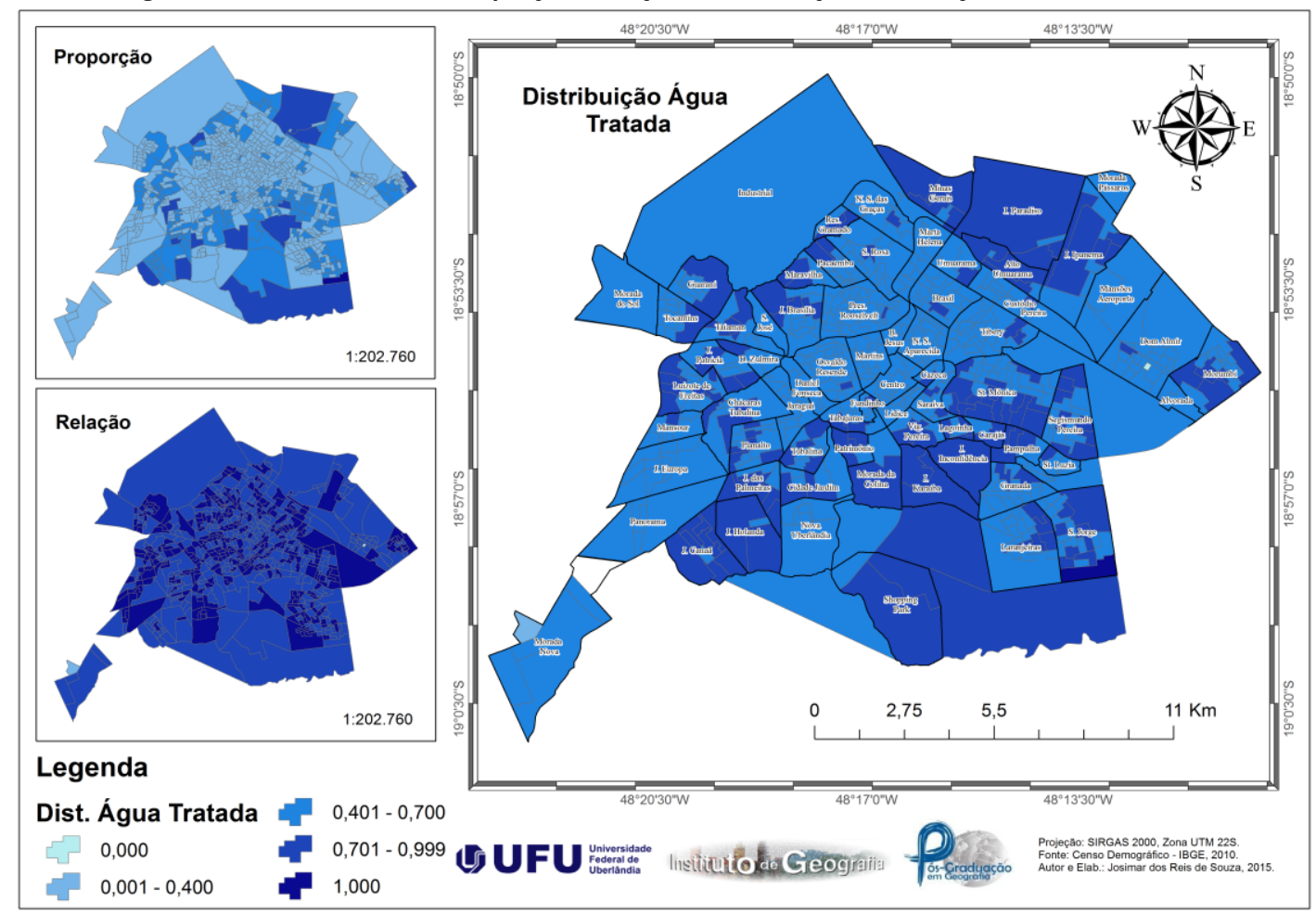

Fonte: IBGE, 2010. Elaborado por: SOUZA, 2015.

A proporção foi analisada a partir da do número de domicílios com acesso a rede de abastecimento de água do setor censitário em relação ao número total de domicílios com acesso a rede de abastecimento da cidade. Essa análise objetivou identificar as áreas da cidade com maior número de domicílios atendidos pelo abastecimento de água.

No ano de 2010 Uberlândia apresentou na maior parte dos setores censitários entre 9 e 334 domicílios com acesso a água tratada (normatização $0,001-0,400$ ). 0 setor censitário com maior número de domićlio atendidos se encontra localizado no bairro São Jorge, e trata do setor com maior número de domicílios da área urbana. Um setor localizado no bairro Dom Almir apresentou ausência desse indicador. Esse setor é composto por 10 domicílios.

A relação do acesso ao abastecimento de água tratada foi analisada a partir do número de domicílios com acesso no setor censitário em relação ao número total de domicílios do setor. Essa relação equivale a densidade de abastecimento. A relação apresentada em Uberlândia em 2010 demonstrou que quase todos setores censitários têm todos os domicílios atendidos pelo abastecimento, com índices igual a 1,000 ou próximos a esse valor.

A distribuição dos domicílios com abastecimento de água foi realizada através da média aritmética dos resultados da proporção e relação. Os resultados apresentaram que a cidade apresenta bons níveis de atendimento desse serviço. O quadro 15 apresenta a análise da distribuição. Os bairros foram classificados em nível alto, médio baixo de distribuição do abastecimento. 
Bairros como Centro, Chácaras Tubalina, Cidade Jardim, Fundinho, entre outros, com nível de renda médio e alto, foram classificados como nível médio por não possuírem todos os domicílios com acesso ao serviço. Entretanto, apresentaram resultados próximos a normatização 1,000 .

Apenas um setor censitário localizado no bairro Dom Almir apresentou índice baixo de abastecimento. Trata-se do setor com pequeno número de habitantes e domicílios, formado por população com baixo nível de renda e com falta de infraestrutura básica. Cabe ao poder público buscar ações visando a melhoria da qualidade de vida nessa área da cidade.

De maneira geral as informações obtidas pelo Censo Demográfico do IBGE (2010) e as do DMAE Uberlândia possuem valores aproximados. Entretanto, a cobertura apresentada pelos resultados do índice somam $96 \%$ dos domicílios atendidos pelo abastecimento e não $100 \%$ conforme apontado pelo DMAE.

A análise da distribuição do número de domićlios com acesso a rede de esgotamento sanitário é relevante na composição do indicador, visto que os níveis de saúde estão diretamente relacionados ao destino dos dejetos produzidos nas residências. O tratamento do esgoto produzido contribui na construção de ambientes urbanos mais saudáveis.

\section{Esgotamento Sanitário}

A figura 11 apresenta os resultados do índice aplicado ao indicador esgotamento sanitário, através da análise da proporção, relação e distribuição.

A proporção foi realizada a partir da análise do número de domicílios com acesso a rede de esgotamento sanitário do setor censitário em relação ao número total de domicílios com acesso na área urbana.

No ano de 2010 a maioria dos setores censitários apresentou entre seis e 335 domićlios com acesso a rede de esgotamento, conforme tabela 46 . O setor com maior número, igual a 837 , se encontrava localizado no bairro São Jorge, correspondendo ao maior setor da cidade de Uberlândia em número de domicílios.

A relação foi analisada a partir do número de domicílios com acesso a rede pelo número total de domicílios do setor. Essa relação equivale a densidade de esgotamento sanitário. $O$ resultado da relação em Uberlândia, na qual a maior parte dos setores censitários apresentaram valores médios $(0,769$ a 0,999$)$ e altos $(1,000)$ de densidade de esgotamento sanitário.

A distribuição da rede de esgotamento sanitário foi obtida pela média aritmética entre a proporção e relação. Dos 69 bairros analisados apenas dois apresentaram setores censitários com nível baixo, Dom Almir e Alvorada. Trata-se de áreas da cidade com problemas sociais e de infraestrutura que necessitam de políticas públicas para a melhoria da qualidade de vida da população. Os dados obtidos nesse estudo se aproximam dos divulgados pelo DMAE, 


\section{Fórum Ambienta}

ISSN 1980-0827

da Alta Paulista

Volume 13, Número 1, 2017

entretanto os aqui encontrados são menores. São $96,4 \%$ dos domicílios atendidos por esse serviço, frente aos 98,32\% apresentados nos dados da prefeitura (BDI UBERLÂNDIA, 2015).

Figura 11: Uberlândia/MG: Proporção, Relação e Distribuição do serviço de esgotamento sanitário

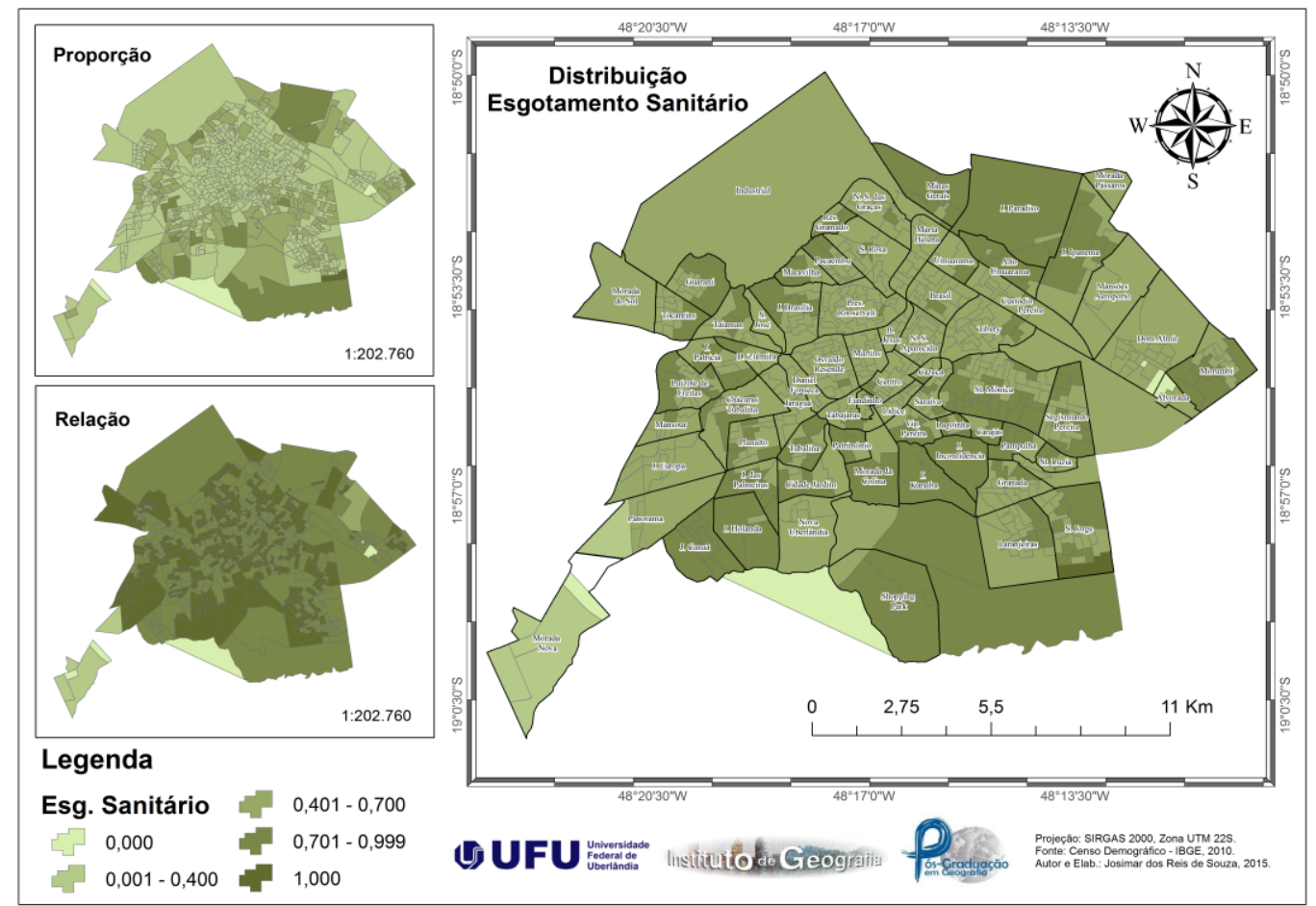

Fonte: IBGE, 2010. Elaborado por: SOUZA, 2015.

Os bons níveis de esgotamento sanitário presentes em Uberlândia não levam em consideração as áreas de ocupação ilegal presentes na área urbana, que não são visitadas pelos recenseadores. Também não contabilizam ligações clandestinas de esgoto. Nesses casos os dejetos produzidos são despejados diretamente nos córregos e no Rio Uberabinha.

A figura 12 foi tirada no Parque Linear do Rio Uberabinha na qual foi possível constatar (pela cor e pelo odor) a existência de ligações de esgoto clandestinas que são conectadas na rede de escoamento pluvial e despejadas dentro da área do parque.

Figura 12: Uberlândia/MG - Ligação de esgoto na rede de escoamento pluvial

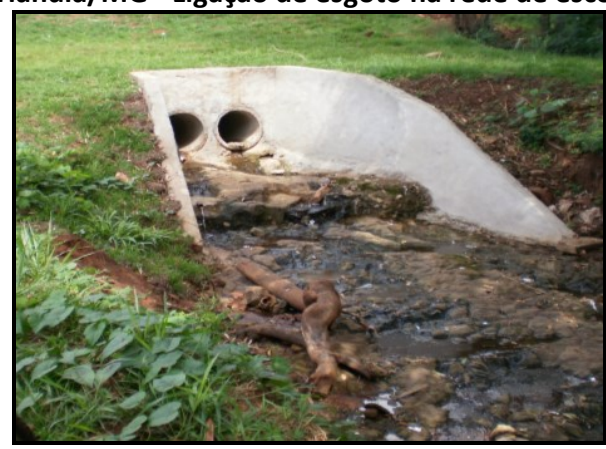

Autor; SOUZA, 2014. 
Apesar de Uberlândia se consolidar com uma das cidades com maior cobertura de esgotamento sanitário faz-se necessário avanços nas políticas públicas para que se possam alcançar cem por cento dos domicílios com acesso a esgotamento sanitário coletado e tratado, contribuindo assim, para a construção de ambientes cada vez mais saudáveis.

\section{CONSIDERAÇÕES}

A partir dos objetivos propostos e resultados apresentados, cabe nesse momento não apenas realizar considerações, mas também, elencar as dificuldades encontradas nas etapas que compuseram o trabalho e a gama de possibilidades e perspectivas que surgiram nessa jornada. Aqui foram evidenciados o histórico dos procedimentos metodológicos, como também, as ideias que surgiram e que serão empregadas no futuro, seja no doutorado ou em outros tipos de pesquisa.

A composição da totalidade da pesquisa explanadas foi resultado do interesse pessoal e acadêmico pelo estudo das cidades. A partir da necessidade de se pensar em novas possibilidades de análise do intraurbano e da paixão pelo modo de vida urbano, a mesma foi desenvolvida com afinco, de modo que se tentasse avançar na perspectiva de buscar estratégias de auxiliassem a construção de Cidades Saudáveis.

Considerou-se que os problemas urbanos preeminentes nas cidades brasileiras poderão ser minimizados e solucionados a partir da busca constante pela melhoria da qualidade de vida, da infraestrutura urbana, do aumento das possibilidades de acesso a serviços e bens de consumo e, sobretudo, pela vontade política e participação social. Ficou evidente, que é papel dos gestores públicos alcançar melhores níveis de desenvolvimento social urbano, contudo, a participação da sociedade nas decisões é preponderante para a construção de ambientes urbanos mais saudáveis.

No jogo de interesses social, público e particular, impera-se a dinâmica do capital, marcada pelas desigualdades socioespaciais, sendo que nas áreas urbanas esses processos se apresentam de forma mais abrangente. Igualmente, a população com acesso reduzido a essa dinâmica, se acomoda em regiões da cidade com maior escassez de equipamentos urbanos. $\mathrm{A}$ essa parcela da população cabe maior atenção da gestão pública, visto que, se parte da cidade não possui bons níveis de qualidade de vida, a mesma como um todo não é saudável.

Em contra partida, tem-se intensificado nos últimos anos ações de busca pela melhoria do ambiente urbano, no qual aqui se destacou o movimento por Cidades Saudáveis. Esse projeto de cidade tem se consolidado sendo importante no contexto contemporâneo, visto que, partes das cidades se encontram doentes, insalubres, com população vivendo em condições de miséria e pobreza. Portanto, se torna urgente a busca pela superação desse quadro. 


\section{REFERÊNCIAS}

ARCGIS. Manual básico de orientações. São Paulo: ArcGIS, 2010. 200 p.

GOLDSTEIN, G.; KICHBUSCH, I. Una ciudad sana es una ciudad mejor. Salud Pública, v. 49, n. 1, 1996, p. 4-6.

GOMES, M. A. S.; SOARES, B. R. Reflexões sobre qualidade ambiental urbana. Estudos Geográficos: Revista Eletrônica de Geografia, Rio Claro, v. 2, n. 2, 2004. p. 21-30.

GUIMARÃES, R. P. Agenda 21 e desenvolvimento sustentável: o desafio político da sustentabilidade. Debates SócioAmbientais, v. 4, n. 11, 2000. p. 10-13.

INSTITUTO BRASILEIRO DE GEOGRAFIA E ESTATÍSTICA (IBGE). Base de informações do Censo Demográfico 2010: Resultados do Universo por setor censitário. Rio de Janeiro: IBGE, 2011. 125 p.

MENDES, R. Cidades Saudáveis no Brasil e os Processos Participativos: Os Casos de Jundiaí e Maceió. 2000. $232 \mathrm{f}$. Tese (Doutorado em Saúde Pública) - Faculdade de Saúde Pública - Universidade de São Paulo, São Paulo, 2000.

MORATO, R. G. Análise da Qualidade de Vida Urbana no Município de Embu/SP. 2004. 108 f. Dissertação (Mestrado em Geografia Física) - USP/FFLCH, São Paulo, 2004.

ORGANIZAÇÃO DAS NAÇÕES UNIDAS (ONU). World Urbanization Prospects The 2009 Revision. Nova lorque: ONU, 2010. 47 p. Disponível em: http://esa.un.org/unpd/wup/Documents/WUP2009_Highlights_Final.pdf. Acesso em: março de 2015.

ORGANIZAÇÃO PARA A COOPERAÇÃO E DESENVOLVIMENTO ECONÔMICO (OCDE). Urban environmental indicators. Paris: OCDE, 1978. $65 \mathrm{p}$.

PROGRAMA DAS NAÇÕES UNIDAS PARA O DESENVOLVIMENTO (PNUD). Índice de Desenvolvimento Humano - IDH. Nova lorque: ONU, 2015.

SOUZA, J. R. Trilhando por Cidades Saudáveis: contribuição metodológica de índice e aplicação em Uberlândia, MG. 265 f. Dissertação (Mestrado em Geografia) - Instituto de Geografia - Universidade Federal de Uberlândia, Uberlândia, 2016.

SOUZA, J. R.; SOARES, B. R. A utilização de Indicadores como suporte à gestão das Políticas Públicas no Brasil. In: Colóquio Ibérico de Geografia, 14., 2014, Guimarães. Anais... Guimarães, Portugal: Departamento de Geografia, Universidade do Minho, 2014. p. 774-780.

WESTPHAL, M. F. O Movimento Cidades/Municípios Saudáveis: um compromisso com a qualidade de vida. Ciência \& Saúde Coletiva, v. 5, n. 1, 2000. p. 39-51, Disponível em: http://www.scielo.br/pdf/csc/v5n1/7078.pdf. Acesso em: agosto de 2015. 